\title{
Os cortadores: registros orais e iconográficos dos trabalhadores imigrantes do Extremo Oeste Baiano no corte sazonal de cana-de-açúctar em Goiás, Brasil
}

The harvesters: oral and iconographic reports from the immigrant workers in the Far West of Bahia during the seasonal harvesting of sugarcane in Goiás, Brazil

\author{
Sandro Dutra e Silva \\ Universidade Estadual de Goiás \\ sandrodutr@hotmail.com \\ Goiânia \\ Brasil
}

Recibido: 22 de abril de 2015

Aprobado: 29 de agosto de 2015

\section{RESUMO}

0 trabalho apresentado é resultado de um projeto de pesquisa envolvendo rurícolas que migram do oeste baiano para trabalhar no corte manual de cana-de-açúcar para a produção sucroalcooleira no município de Itapaci, Estado de Goiás. Essa região passou a ser ocupada durante expansão agrícola da década de 1940, na política da Marcha para 0 Oeste. 0 trabalho baseia-se na análise da iconografia e nos depoimentos dos cortadores. Dentre os temas e abordagens destacadas relacionamos as questões socioambientais da expansão agrícola no Cerrado e as migrações de mão-de-obra nordestina para 0 exercício dessa atividade em Goiás. 0 trabalho procura relacionar a trajetória dos cortadores com as imagens produzidas, identificando os elementos econômicos e socioambientais apontados nos depoimentos dos rurícolas entrevistados.

\section{PaLAVRAS-ChaVe}

Cana-de-açúcar; cerrado; migração; meio-ambiente; rurícolas; socioambientalismo.

\section{ABSTRACT}

This study is a result of a research project on rural workers who migrated from the state of Bahia to work as harvesters on sugarcane plantations, for the production of etanol in Itapaci, state of Goias. This region was occupied during the agricultural expansion of the 1940's which was part of the "March to the West" policy. This study was based on the iconographic analyses of testimonies from the rural workers. Within the topic and approaches highlighted, this study works to relate social and environmental questions to the agricultural expansion of the Cerrado and the migration of northeastern laborers to accomplish such a feat in Goiás. This study also looks to relate the trajectory that the harvesters had along with the images developed, being these the identification of economic elements as well as noting the social and environmental testimonies given by the rural workers during their interviews. The iconographic scenes portray the daily lives of the harvesters, showing the relationship between society and nature on the sugarcane plantations of Goiás.

\section{KEYWORDS}

Sugarcane; cerrado; migration; environment; rural workers; social environmentalism. 


\section{Introdução}

A produção de cana-de-açúcar esteve presente na história econômica brasileira desde o século XVI. 0 processo de colonização portuguesa do território brasileiro, que pode ser também identificado como um fenômeno ecológico, ${ }^{1}$ caracterizou-se na dispersão de plantas e animais, introduzidos como recursos bióticos para 0 domínio e transformação das paisagens tropicais. ${ }^{2} 0$ historiador ambiental Warren Dean ${ }^{3}$ considera que os portugueses "se tornaram os agentes da dispersão, no Brasil, de uma flora tropical que Ihes era estranha, implantando-a em outro domínio natural que consideravam como sua conquista". Além da introdução de plantas exóticas como a cana-de-açúcar, favoreceu o domínio colonial, que desse ponto de vista pode ser entendido como um domínio essencialmente ecológico.

A cana-de-açúcar pode ser identificada, no processo de domínio ecológico da colônia portuguesa, como a mais valiosa planta introduzida durante o período colonial, na medida em que o seu cultivo e derivados permitiu a viabilidade do projeto mercantilista do colonizador. Domesticada e cultivada na Índia e também plantada na região do Mediterrâneo, essa planta foi o principal produto de exportação da colônia portuguesa para o norte da Europa durante o período mercantilista. ${ }^{4}$ Ao mesmo tempo ela representou alterações significativas na paisagem tropical brasileira, sobretudo na Mata Atlântica. Os estudos de Dean consideram que os perigos da produção canavieira para a Mata Atlântica foram evidentes e de grandes proporções, na medida em que "uma sociedade baseada na mão-de-obra compulsória não levava em conta 0 ambiente" ${ }^{5}$ Além da devastação de áreas florestadas a economia colonial açucareira buscou adaptar o modelo de plantation escravagista, adotado pelos europeus no Novo Mundo tropical. As paisagens dominadas pelas plantações de cana-de-açúcar expunham um sistema agrícola baseado no tripé do latifúndio, monocultura e no trabalho escravo. ${ }^{6}$

Para Dean, a economia açucareira não se esgota e seus efeitos sobre as paisagens, são percebidas ao longo dos séculos XVII, XVIII e XIX, adentrando o interior do território. Nesse sentido, são várias as imagens produzidas por viajantes europeus que descrevem as paisagens e os processos produtivos dominados pelas plantações canavieiras. São imagens clássicas que compõem a histórica iconográfica do Brasil, em que os componentes do sistema colonial como o latifúndio, a monocultura e a escravidão aparecem retratadas em pinturas e desenhos. Engenhos, plantações, escravos, moendas, cortes de cana, castigos, a fabricação do açúcar, fazendas, dentre outras imagens, ajudaram a construir um conjunto iconográfico representativo da sociedade e do sistema produtivo da atividade canavieira no Brasil, tanto no período colonial (1500-1822) quanto durante os primeiros anos do Império no Brasil (1822-1889). Destacamos os trabalhos Franz Post (1612-1680), Albert Eckhout (16101666) Jean-Baptiste Debret (1768-1848), Johann Moritz Rugendas (1802-1858), dentre outros, em que a produção canavieira foi retratada e compôs um registro iconográfico desse período no Brasil. Esses registros iconográficos fazem parte da memória e da identidade cultural do país.

Este trabalho não tem, nem de longe, a mesma pretensão artística e cultural dos demais trabalhos sobre a constituição iconográfica da atividade canavieira no Brasil. Inclusive, essa não era a intenção inicial do projeto de pesquisa. 0 arquivo fotográfico que compõe essa galeria não visava, no seu projeto inicial, constituir uma base iconográfica da atividade canavieira na microrregião de Ceres em Goiás, antiga área florestada do chamado "Mato Grosso de Goiás" no século XXI. As imagens que compõem essa galeria fizeram parte de um projeto de pesquisa intitulado "As transformações do Cerrado e suas implicações socioambientais". 70 Projeto tinha como objetivo geral analisar a evolução dos processos de mudanças da cobertura do solo em áreas de cerrado no Estado de Goiás e seus impactos socioambientais, a partir da década de 1970. A proposta era investigar o novo avanço da fronteira agrícola e das monoculturas, como a-da cana-de-açúcar, e as mudanças nos padrões das lavouras na

\footnotetext{
${ }^{1}$ Crosby, Alfred W. Imperialismo ecológico: a expansão biológica da Europa, 900-1900. (Companhia da Letras, São Paulo: 2011)

${ }^{2}$ Dean, Warren. A ferro e fogo: a história e a devastação da Mata Atlântica brasileira. (Companhia das Letras São Paulo: 1996)

${ }^{3}$ Ibid., p. 73

${ }^{4}$ lbid.

5 Ibid., p. 74

${ }^{6}$ Prado Junior, Caio. História Econômica do Brasil. (Brasiliense, São Paulo: 2006)

${ }^{7} 0$ projeto de pesquisa esteve vinculado à Coordenadoria de Aperfeiçoamento do Pessoal do Ensino Superior - CAPES, por meio do Programa Nacional de Cooperação Acadêmica Novas Fronteiras (PROCAD-NF). O PROCAD-NF foi realizado por parceria estabelecida entre Programa de Pós-Graduação em Sociedade, Tecnologia e Meio Ambiente do Centro Universitário de Anápolis (PPSTMA/UniEVANGELICA) e o Programa de Pós-Graduação em Geografia da Universidade Federal de Uberlândia.
} 
microrregião de Ceres em Goiás. Assim, as imagens que compõe esse trabalho foram produzidas em missões de pesquisa e não com a finalidade artística e cultural da representação iconográfica da atividade canavieira em Goiás e seus efeitos socioambientais. As imagens foram produzidas em pesquisa de campo realizada no município de Itapaci, Goiás, no mês de setembro de 2011. As fotografias foram feitas por um dos bolsistas do projeto, Tiago de Oliveira Rabelo, produzidas no equipamento Cânon Rebel XS. ${ }^{8}$

\section{A produção canavieira em Goiás}

A presença da produção canavieira no interior do Brasil foi descrita por viajantes que registaram a ocorrência de pequenas engenhocas em Minas Gerais e em Goiás no século XIX. Particularmente, no caso do território goiano, a localização e características geográficas (um vasto planalto no interior do Brasil), tornavam difícil a introdução de equipamentos e tecnologias para a produção da atividade canavieira em larga. Devido a carência de estradas e da precária base hidrográfica que favorecessem a circulação de mercadorias e equipamentos, essa atividade se desenvolveu de forma artesanal, nas pequenas engenhocas existentes. Esse vasto território, descrito pelo historiador americano David McCreery ${ }^{9}$ como a fronteira da fronteira, era o lugar mais isolado e o sertão de mais difícil acesso no Brasil no século XIX. No entanto, alguns relatos de viajantes indicavam a presença da atividade canavieira em Goiás. Destacamos os relatos de Saint-Hilaire ${ }^{10}$ sobre 0 engenho de cana na fazenda do Comendador Joaquim Alves de Oliveira, na cidade de Meia-Ponte (atual Pirenópolis). A grande quantidade de escravos e a dinâmica da atividade canavieira chamaram a atenção do viajante francês. Com uma narrativa etnocêntrica, o viajante relacionava a ordem doméstica presenciada naquela fazenda com as que são comumente observadas nas regiões de clima temperado. 0 engenho, anexo à casa, desempenhava um papel importante na economia da fazenda, assim como a plantação de algodão e mandioca. 0 engenho hidráulico se assemelhava ao modelo produzido pela gravura clássica de Rugendas (Imagem 1). Saint-Hilaire assim descreve: "0 engenho-deaçúcar, conjugado à casa, fora construído de maneira que, da sala de jantar, pudesse ser visto o trabalho que se fazia junto às caldeiras, e da varanda, o que se passava no moinho da casa". ${ }^{11}$ A produção de açúcar dessa fazenda tinha por finalidade abastecer o consumo interno da casa, e parte da produção de cachaça e açúcar era vendida nos vilarejos da região de Meia Ponte e da capital goiana. Assim, ainda que não fosse a principal atividade da fazenda, cumpria um papel importante na renda desta e também era significativo para 0 abastecimento das vilas e povoados da Província de Goiás.

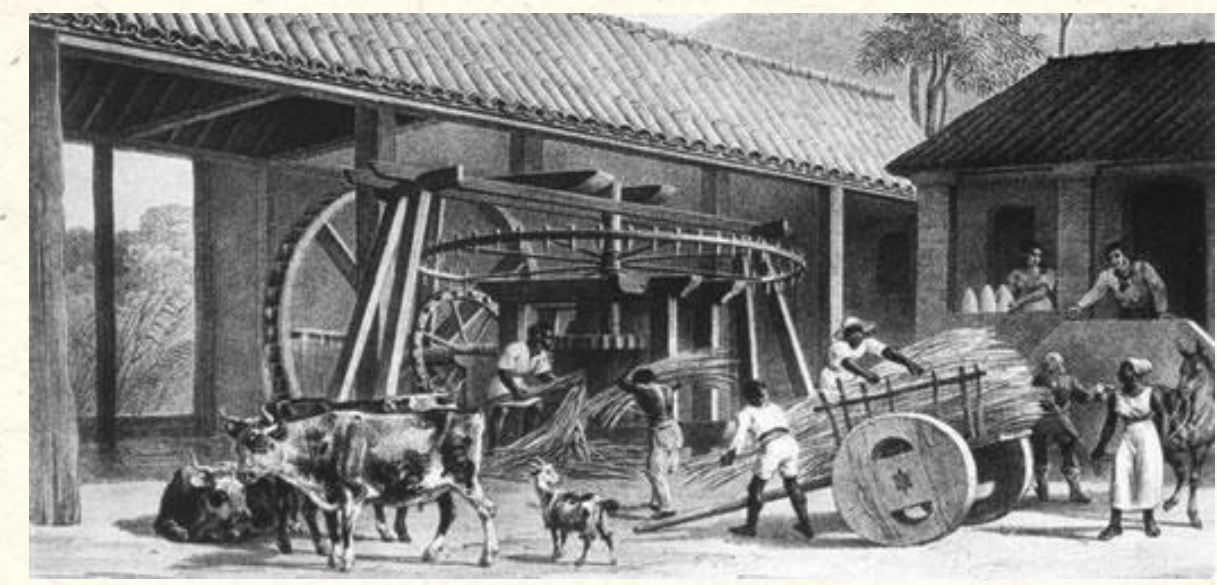

Imagem 1 - Engenho de Acúcar, por Johann Moritz Rugendas, 1835 (Gravura).

De acordo com um estudo publicado na Revista Brasileira de Geografia em 1950, ${ }^{12}$ a produção canavieira no Planalto Central do Brasil tinha importância secundária, chegando a assumir 0 aspecto de cultura de

\footnotetext{
${ }^{8}$ Atualmente essas imagens fazem parte do acervo permanente do PPSTMA.

${ }^{9}$ McCreery, David. Frontier Goiás, 1822-1889. (Stanford University Press, Stanford, Califórnia: 2006)

${ }^{10}$ Saint-Hilaire, Auguste de. Viagem à Província de Goiás. (Ed. Itatiaia, Belo Horizonte; Ed. da Universidade de São Paulo, São Paulo: 1975)

${ }^{11}$ Ibid., p. 98

12 Simões, Ruth Mattos Almeida. Interpretação do mapa de produção, de cana de açúcar no sudeste do planalto central. Revista Brasileira de Geografia. Ano XII, JulhoSetembro de 1950, n. 03, pp. 371-382
} 
subsistência. A atividàde tinha dificuldade de abastecimento dos mercados locais, que importavam os derivados da cana-de-açúcar dos estados de São Paulo e de Minas Gerais. Era comum a existência de pequenos engenhos dedicados à produção de aguardente e rapadura. 0 açúcar beneficiado, no entanto, era produzido no Sudeste e importado pelos goianos.

A produção de cana-de-açúcar em Goiás não exigia um tipo de solo específico para o plantio, mas abundância de calor e umidade. No entanto, em terrenos de solos com maior acidez 0 desenvolvimento da planta não era satisfatório, pois o caldo apresentava um grau elevado de impurezas e uma qualidade inferior no processo de industrialização dos derivados. Apesar de ser pouco exigente em relação aos solos, a cultura se desenvolveu em Goiás em terrenos argilosos e nas "terras ricas em matéria orgânica, onde o húmus é uma fonte de riqueza para a agricultura, e também (n)os solos de origem vulcânica". ${ }^{13}$ Dessa forma, os dados de 1945 indicavam que no Planalto Central (incluindo áreas de Goiás e Triângulo Mineiro), a maior produção canavieira concentrava-se em três áreas específicas, que tinham em comum a fertilidade do solo e a região florestada, cujas matas eram derrubadas para o plantio. Simões destacava as seguintes áreas: i) a região dos vales dos rios Grande e Paranaíba, região de Mata Atlântica e solo fértil, proveniente da decomposição de rochas vulcânicas; ii) zona da Mata da Corda em Goiás, também com ocorrência de tufos vulcânicos; iii) e a região florestada do "Mato Grosso de Goiás", descrita como zona favorecida pela ocorrência de rochas básicas antigas. As regiões florestadas indicavam, nesse período, um processo intenso de migração. Os novos colonos buscavam as regiões de floresta para a promoverem a derrubada das matas para a atividade agrícola. Sobre a região do Mato Grosso de Goiás, o estudo aponta que essa região era:

um núcleo de colonização que se vem desenvolvendo rapidamente nos últimos anos, com a chegada de colonos, quer mineiros, quer paulistas, ou mesmo goianos de outras regiões do estado. 0 móvel da colonização é 0 aproveitamento das terras de matas para o plantio do arroz e do café, sendo a cana de açúcar uma cultura subsidiária. [...] A lavoura desenvolve-se nos trechos onde a mata foi derrubada, principalmente nas encostas dos vales, onde a cana melhor se adapta, porém não assume a importância do arroz e do café, os dois principais produtos no "Mato Grosso de Goiás". ${ }^{14}$

0 estudo de Simões considerava quee produção canavieira, apesar de ser uma cultura que em sua maioria era de subsistência, vinha assumindo importância nos locais de maior adensamento populacional em função da migração, como no caso da região do Mato Grosso de Goiás. Em termos industriais, no entanto, era uma produção de pouca expressão, pois os engenhos locais se dedicavam, principalmente, à fabricação de aguardente, rapaduras e açúcar mascavo. 0 açúcar refinado era importado das usinas paulistas. Com relação ao uso do solo na produção, considerava esse um fator importante na explicação da distribuição da produção, sobretudo na região do Mato Grosso de Goiás: a fertilidade do solo e a distribuição populacional estavam relacionadas ao avanço da atividade canavieira. ${ }^{15}$

0 Mato Grosso de Goiás era uma grande área de floresta tropical estacional, com uma área estimada de 20.000 Km2, e que passou a ser colonizada na década de 1930, motivada pela construção de Goiânia (1933) e pela chegada da ferrovia em Anápolis (1935). Essas cidades estavam localizadas à borda dessa região florestal. A valorização das terras e as políticas de colonização e migração promovidas pelo governo federal na "Marcha para o Oeste", favoreceram a ocupação das matas e o seu consequente desflorestamento. Uma das áreas que mais sofreu impacto dessa ocupação foi a região das Matas de São Patrício, localizadas na parte norte do Mato Grosso de Goiás, cujas terras foram doadas ao governo federal para a implantação da Colônia Agrícola Nacional de Goiás. ${ }^{16}$

A história ambiental dessa antiga região florestada, sobretudo nos estudos que trabalham com a ocupação e 0 uso do solo, tem evidenciado uma transformação significativa nas paisagens naturais. ${ }^{17}$ As fontes utilizadas para descrever 0 estágio de devastação florestal e os novos usos do solo identificam a ampliação de áreas para

\footnotetext{
${ }^{13}$ Ibid., p. 373

14 Ibid., p. 377

${ }^{15}$ Idem

${ }^{16}$ Silva, Sandro Dutra e. Os estigmatizados: distinções urbanas às margens do rio das Almas em Goiás (1941-1959). (Tese de Doutorado). Programa de Pós-Graduação em História. Brasília, Universidade de Brasília, 2008.

17 Ver: Silva, Sandro Dutra; Oliveira, Luís Fernando; Mendes, Cassio Mauricio. Legislação e História Ambiental: a expansão sucroalcooleira na microrregião de Ceres em Goiás. Mediação (UEG. Pires do Rio), v. 7, 2012, p. 11-26. Ver ainda: Sandro Dutra e Silva; Maria Gonçalves da Silva Barbalho; José Luiz de Andrade Franco. A expansão sucroalcooleira e a devastação ambiental nas matas de São Patricio, microrregião de Ceres, Goiás. história, histórias. Brasília, vol. 1, n. 1, 2013; pp. 230-247
} 
as pastagens e áreas àgricultáveis. Observa-se, ainda, 0 avanço da mecanização intensiva e 0 uso da irrigação na agricultura. A produção sucroalcooleira tem contribuído, significativamente, para os novos usos do solo para a agricultura. Além dos trabalhos dos historiadores ambientais, os geógrafos, sobretudo por meio dos trabalhos realizados pelo Instituto de Estudos Socioambientais - IESA, da Universidade Federal de Goiás, com 0 uso da geotecnologia e outras ferramentas de sensoriamento remoto, têm destacado os efeitos da produção de cana no ambiente natural. ${ }^{18}$

\section{Os cortadores}

A região mais ao norte do antigo Mato Grosso de Goiás, nas áreas de influência da Colônia Agrícola Nacional de Goiás, é uma área de intensa produção sucroalcooleira atualmente. Essa região é atualmente conhecida como microrregião de Ceres e abriga em seu território várias usinas para a produção de açúcar e etanol. ${ }^{19} \mathrm{~A}$ partir de um conjunto de dados que temos sobre o impacto da produção sucroalcooleira no ambiente florestal da microrregião de Ceres, nos interessou compreender outro viés dessa atividade agrícola. Um dado relevante era a utilização do corte manual da cana em toda microrregião e a utilização do trabalho sazonal de cortadores. Esses cortadores, em sua maioria, chegavam do Extremo Oeste baiano e passavam uma temporada de seis meses nas cidades da microrregião. Eram contratados em sua região de origem e há quase uma década, sobretudo a partir da retomada da produção da cana nos primeiros anos do século XXI, após a crise do Programa Nacional do Álcool (PROÁLCOOL) na década de 1990. ${ }^{20}$ Os cortadores sazonalmente faziam esse trajeto entre a Bahia e Goiás. Os contratantes se obrigavam a fornecer transporte e moradia durante o período do corte da cana nas áreas de plantio. Os cortadores chegavam no início do período de estiagem (abril/maio) e retornavam no início do período chuvoso, quando a atividade do corte era paralisada (outubro/novembro). Esse período poderia ter uma variação de acordo com a estação, podendo ser maior ou menor do que seis meses. 0 corte manual em Goiás, apesar da regulamentação sobre o fim da atividade em função da mecanização, ${ }^{21}$ ainda é muito utilizado na microrregião de Ceres, sobretudo nos municípios de Itapaci, Nova Glória, Rubiataba e Carmo do Rio Verde. Na cidade de Goianésia a mecanização vem ganhando força, apesar de contar com a presença de um grande efetivo de mão-de-obra sazonal.

As imagens que compõem essa galeria foram fruto desse trabalho de campo (no ano de 2011) com os cortadores imigrantes que tinham sede temporária na cidade de Itapaci e que foram contratados para 0 trabalho na Usina Vale Verde para a safra daquele ano (Imagem 2). No que se refere às condições de trabalho para a atividade sucroalcooleira, verificamos existir uma quantidade pequena de registros e processos relacionados à incidência de trabalhos análogos à escravidão. No entanto, constatamos que as condições de trabalho dos cortadores eram extremamente penosas, sobretudo no que se refere ao esforço físico e as condições ambientais. De acordo resoluções do Centro de Apoio Operacional do Meio Ambiente (CAOMA) do Ministério Público do Estado de Goiás, a queima e 0 corte deveriam ser proibidas quando as condições ambientais são consideradas ameaçadoras para a saúde humana. Um dos fatores apontado como condição para a paralização da atividade é a baixa umidade relativa do ar. No período de estiagem, sobretudo entre os meses de agosto a outubro, esses níveis chegam a estágios críticos no período vespertino. Quando a umidade relativa do ar atingir níveis abaixo de 30\% considera-se estágio crítico e necessário para a paralisação das atividades de corte, que exigem esforço físico e são prejudiciais à saúde dos cortadores. No entanto, as pesquisas de campo, que resultaram nas imagens que compõem essa galeria, evidenciam o descumprimento dessas normas e de outras relacionadas aos direitos humanos. ${ }^{22}$

\footnotetext{
${ }^{18}$ Ferreira, L.C.G. A evolução do setor sucroalcooleiro na Microrregião de Ceres-GO: dinâmica espacial e impactos socioeconômicos. Dissertação. Programa de PósGraduação em Geografia. UFG. 2010

${ }^{19}$ Silva, Sandro Dutra et al, op. cit., 2013

${ }^{20}$ Baccarin, José Giacomo. A Constituição da Nova Regulamentação Sucroalcooleira. Brasília: Universidade de Brasília, Centro de Estudos Avançados Multidisciplinares, Núcleo de Estudos Agrários; São Paulo: Editora UNESP, V. 5, n² 22, 2005

${ }^{21}$ Moreno, Luiz Marcelo. Transição da colheita de cana-de-açúcar manual para a mecanizada no estado de São Paulo: cenários e perspectivas. (Mestrado). Programa de Pós-Graduação em Energia, Escola Politécnica, Faculdade de Economia e Administração, Instituto de Eletrotécnica e Energia, Instituto de Física. Universidade de São Paulo, 2011

22 Silva, Sandro Dutra et. al, 2012
} 
A Usina Vale Verde concedeu permissão à equipe de pesquisadores para a realização de entrevistas com os cortadores. A nossa solicitação era que essas entrevistas fossem realizadas nas lavouras, e que também pudéssemos fotografar os trabalhadores no exercício de sua atividade. Essa autorização ocorreu após uma longa tentativa de contato com os gestores da empresa. A equipe, no entanto, foi conduzida a uma lavoura escolhida pela empresa pelos encarregados da usina. Esses encarregados fizeram a seleção dos cortadores para as entrevistas, cujo teor das questões havia sido previamente apresentado e acordado com os representantes da Usina. Eram questões abertas e objetivas sobre a história de vida desses cortadores, considerando a sua origem e a vivência no trabalho do corte manual. As condições de trabalho e outras questões que pudessem envolver demandas judiciais foram evitadas (uma forma mais polida de se dizer que foram proibidas). Os cortadores também manifestaram o seu consentimento em participar da pesquisa e das fotografias.

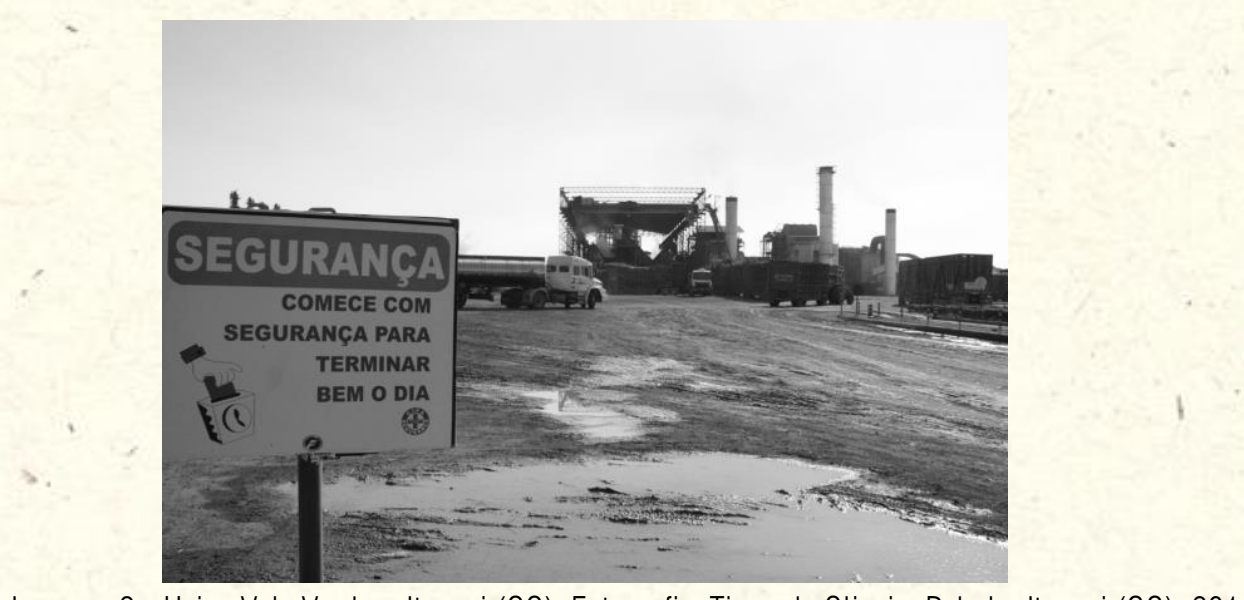

Imagem 2 - Usina Vale Verde - Itapaci (G0). Fotografia: Tiago de Oliveira Rabelo, Itapaci (G0), 2011

As condições impostas para as entrevistas, bem como a forma de abordagem dos sujeitos (eleitos pelos encarregados da usina), poderia comprometer a pesquisa e o uso mais efetivo da oralidade. Questionamos os motivos da eleição de alguns cortadores em detrimentos de outros. Por que os encarregados indicavam os cortadores que seriam entrevistados? Esse fato pode ser um indicio de que na verdade as condições podem ser ainda piores do que 0 verificado. Eles apareciam do meio da lavoura trazidos por esses encarregados, que permaneciam presentes durante toda entrevista. Dessa forma, não questionamos a veracidade das falas, nem a trajetória de vida dos trabalhadores entrevistados, mas o processo de escolha. Nossa opção foi tratar de assuntos que diziam respeito não às relações de trabalho, mas a experiência na migração, sua vida na região de origem, a relação com a comunidade goiana, dentre outras. Quando relacionamos ao trabalho procuramos perceber as atividades em si, as questões com 0 ambiente e com o corte efetivo, a rotina.

A princípio achávamos que as entrevistas haviam perdido o sentido inicial das propostas do projeto geral. No entanto, pudemos perceber que esses relatos eram pertinentes e relevantes do ponto de vista social e, ao mesmo tempo, que o material coletado nas entrevistas e a imagens captadas retratavam um contexto até então desconhecido. A identificação de um grupo grande de trabalhadores que migravam do sertão baiano para Goiás para uma atividade que era sazonal, mas que se repetia havia mais de uma década, a informação de que o grupo se reproduzia entre os familiares e que atravessava uma geração recente eram dados novos e que se apresentavam relevantes do ponto de vista científico. E as imagens se apresentavam estética e socialmente relevantes. A força do material iconográfico retrata um fenômeno novo no processo da expansão da fronteira agrícola canavieira na região de Ceres. Essas imagens, são, também, testemunhas de uma atividade com tempo marcado para extinção (considerando que existe uma previsão para o fim do corte manual), mas que ainda dá sinais de forte perpetuação nas lavouras queimadas no Vale do São Patrício (nome mais usado para a microrregião de Ceres) em Goiás. Da mesma forma, alguns elementos da oralidade também podem evidenciar esse fenômeno, como forma de caracterizar as condições de vida e a trajetória desses sujeitos. Iremos utilizar nesse texto parte do material coletado no trabalho com a oralidade, em um diálogo com a trajetória de vida e da atividade do corte manual. As imagens escolhidas para compor essa galeria estão relacionadas com a temática da oralidade e serão apresentadas no final do trabalho. 
Uma personagèm que pode retratar bem a trajetória dos trabalhadores imigrantes é um cortador que aqui damos o codinome de "Baiano" (Imagem 3), que já fazia o percurso entre o nordeste e o centro-sul do Brasil havia mais de dez anos. Ele era natural de Santana dos Brejos e iniciou as suas atividades no corte da cana em Catanduva e em Bebedouro, no estado de São Paulo em meados da década de 1990. Ele fazia parte de um grupo de cortadores do chamado Extremo Oeste Baiano, principalmente das localidades de Serra do Ramalho, Santana, Tabocas do Brejo Velho e Serra Dourada. Em 2004 ele começou a trabalhar nas safras goianas, nas lavouras em Inhumas, Anicuns, Americano do Brasil. Nesse trabalho ele conheceu o atual encarregado, que trabalhava na contração dos trabalhadores na Bahia para a safra da cana em Goiás. Muitas das informações dadas por Baiano eram repetidas pelos demais. Mas em grande parte, por ser o mais antigo cortador, adquiria uma função de liderança entre os demais. Esses trabalhadores quando não estavam no trabalho do corte da cana nas lavouras em Goiás viviam da agricultura em sua região de origem, sobretudo do plantio do milho, feijão e mandioca. Nas palavras de Baiano "agora, planto é a gente colhe umas coisinhas né. Aí a gente pega bico, pega empreite, pega uma roça pra roçar e novamente segue a vida desse jeito. E quando a gente vem no corte de cana é mais sossegado, porque a gente ganha o dinheiro pra passar o final de ano junto com a família, né? (sic)". 0 trabalho no corte da cana em Goiás era responsável pelo sustento e pela melhoria das condições de vida desses trabalhadores baianos. Muitos alegavam que as economias oriundas do corte da cana eram utilizadas para dar uma vida mais confortável para os familiares. No entanto, muitos afirmavam que o rendimento adquirido em Goiás era, muitas vezes, utilizado para o tratamento médico familiar. Segundo um cortador, os gastos com tratamento médico de familiares é significativo e que "como a gente tá mexendo provavelmente com doença, sobra um pouquinho pra gente poder comprar um pedaço de terra, um lote na cidade ou completar pra gente comprar uma casa na cidade, alugar, né? (sic)".

Dentre os motivos da migração para as lavouras em Goiás apontam a falta de chuva para a lavoura e a pouca oferta de trabalho na sua região de origem. Alguns poucos conseguiam emprego em uma empresa do ramo cafeeiro em Santana. No entanto, os que conseguiam essa colocação eram os que conseguiam superar as exigências da escolaridade. Os que tinham um nível escolar inferior acabavam migrando para a atividade do corte da cana em Goiás: "como a gente, o estudo é mais fraco. E parece que já tem aquela cabeça também de vim pro corte. Aí a gente provavelmente vem pro, corte (sic)". Sobre o fim da queima e do corte manual e as novas exigências legais para o corte mecanizado, esses cortadores afirmam que concordam, pois os danos ambientais e 0 desgaste físico pelo trabalho manual são significativos. No entanto, muitos reconhecem que estarão fora da atividade, em função das exigências de uma formação escolar e profissional para o novo cenário de colheita mecanizada.

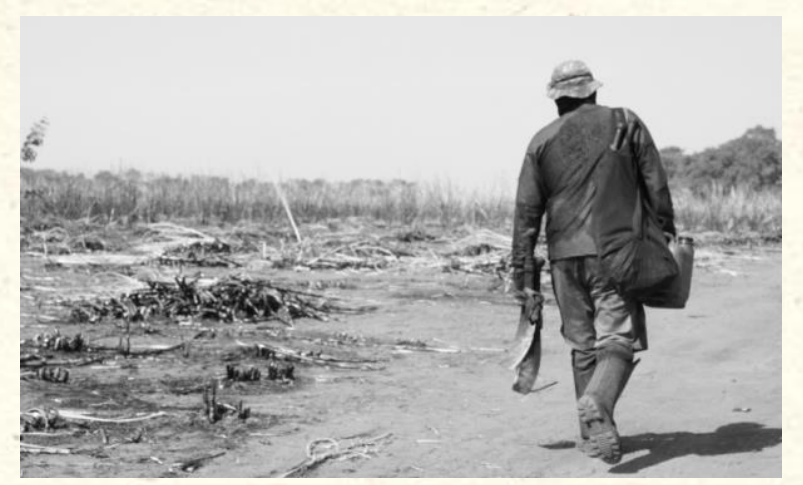

Imagem 3 - 0 cortador do Extremo Oeste Baiano. 0 cortador, por codinome "Baiano", que acumula experiências no trabalho sazonal do corte da cana no Sudeste e Centro-Oeste do país, havia deixado o seu "taião" para nos conceder uma entrevista. Logo após a entrevista, que deve durou em média 40 minutos, ele retornou ao seu trabalho. A imagem lembra um soldado indo para a sua batalha. Armado de "podão", carregando a sua garrafa de água, segue para o seu "taião". Fotografia: Tiago de Oliveira Rabelo, Itapaci/G0, 2011.

A rotina de trabalho foi descrita como árdua e os trabalhadores eram pagos pela produção. Ou seja, um trabalho penoso, mas que a produtividade dependia, justamente, do maior esforço físico despendido. Os cortadores afirmaram que existem lavouras em que a cana tem melhor qualidade, é mais pesada, e, portanto, conseguem receber um preço melhor pela produção. Mas nas lavouras em terreno mais pedregoso o preço do trabalho era menor, porque a qualidade da cana é inferior, e isso reflete no peso e no pagamento final da mão-de- 
obra. Essa equação era de se fazer o mesmo esforço, mas com um resultado inferior. 0 Baiano explica esse processo da seguinte forma: "Produção, metragem, né? Caso, quem corta mais, mede. Quem corta menos, tudo é medido. Aí tem seu valor de preço de cana, que é por metro, né? É assim. Uma cana dessa aqui, realmente no dia eu faço oitocentos, mil e poucos metros (sic)"..

Sobre os danos físicos atividade do corte os entrevistados afirmavam que as condições de trabalho e as características da lavoura acabam resultando em lesões e outras perturbações. Isso se dava pela necessidade em manter a produção, que era valorada pela métrica da cana cortada (Imagem 4). Isso colocava os cortadores em uma competição interna, em que a produção não poderia ser inferior à média dos demais cortadores. Nesse sentido, mesmo em condições físicas desfavoráveis precisavam manter a média da produção. De acordo com um relato, essa média na métrica da cana deveria ser superior a mil metros diários: "Ontem mesmo eu tirei mil e poucos metros aqui detrás aqui".

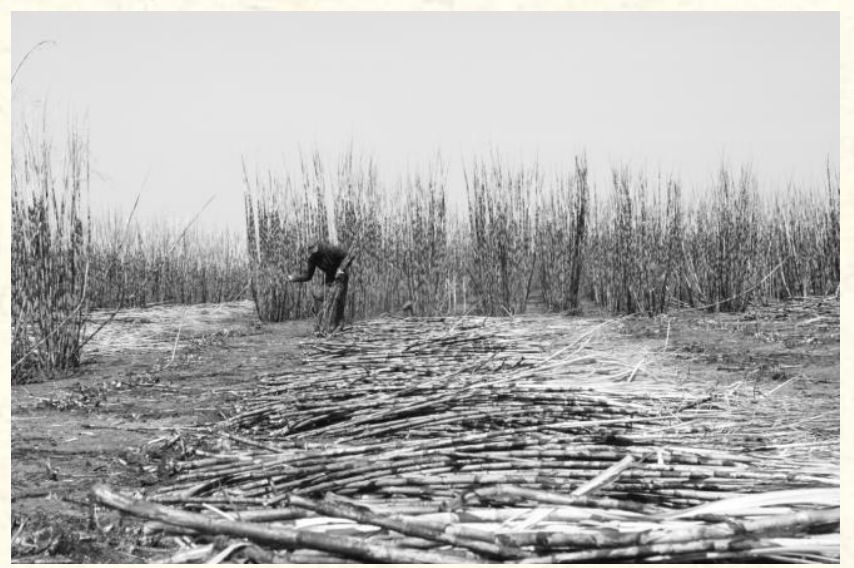

Imagem 4 - "Tirando o taião": 0 processo de corte manual segue um território previamente definido, os lotes, ou os "taião", como eles dizem. "Tirar o taião" significa, cortar a cana previamente definida nos lotes. Posteriormente serão medidos e o preço também é pago pelo peso, ou qualidade da cana. Fotografia: Tiago de Oliveira Rabelo, Itapaci (G0), 2011.

Os cortadores denominam de "Taião" o lote no qual cada rurícola teria por sua responsabilidade. Uma vez cortada a cana, a produção era medida por um encarregado da Usina, que anotava a quantidade produzida em cada "Taião" (Figura 5). Chamam de "traia" as suas vestimentas, que incluíam, além das roupas e equipamentos de proteção, os utensílios de corte, o "podão", e uma garrafa térmica para água potável. Mesmo equipados com luvas e equipamentos e proteção eles afirmavam sentir fisicamente a jornada de "tiragem" da cana nos trechos da lavoura. Geralmente a lavoura em que o corte era iniciado havia sido queimada na véspera. Como 0 corte era realizado nos meses de estiagem do cerrado, justamente quando a umidade relativa do ar estava abaixo dos níveis recomendados, a sensação de cansaço e desgaste físico se intensificava.

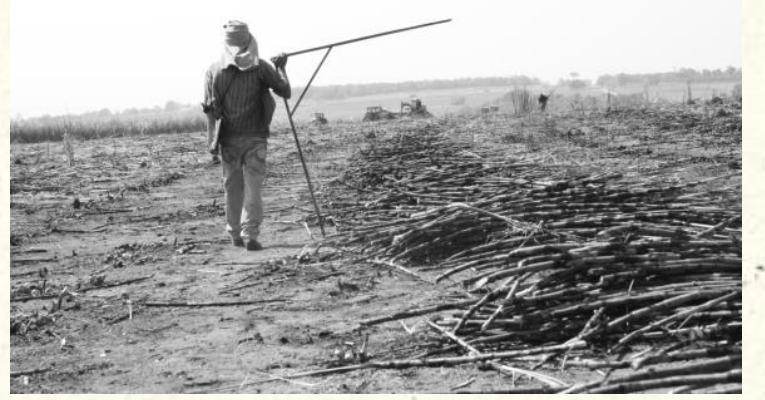

Imagem 5 - 0 ponteiro. 0 "ponteiro", que geralmente é um trabalhador local da Usina, efetua a metragem dos lotes cortados naquele dia. Ao fundo, o trabalho das maquinas carregadoras, que irão carregar os "treminhões". Logo após, esses veículos saem transportando a cana para a Usina, onde serão beneficiadas para a produção de açúcar e etanol. Fotografia: Tiago de Oliveira Rabelo, Itapaci (G0), 2011.

Os calos nas mãos, o equipamento pesado, a baixa umidade relativa do ar, as cinzas do canavial queimado e 0 calor escaldante das tardes secas dos mes̄es de maio a outubro, tornam essa atividade, em termos de esforço 
físico, muito penosa. Um cortador afirmou que: "a gente fica pra trás porque num aguenta acompanhar. Porque quebra mais, machuca mais, porque tem hora que rala mais, esforça mais do que 0 outro. E o sol que nem tá agora no mês de setembro, ele é muito quente. [...] Que esse esforço aqui, faz esforço de qualquer maneira. Você esforça pra baixar, você esforça pra tirar o ponteiro, você esforça pra pegar a cana, abraçar, como você tá vendo, né, a situação. (sic)".

Os cortadores têm consciência dos cuidados que devem ter, não apenas em relação à segurança e aos riscos no manuseio das ferramentas, mas também com o corpo. 0 filtro solar e o consumo regular de água já fazem parte da sua rotina. 0 consumo de água potável é garantido pela Usina, sendo que cada um carrega a sua própria garrafa térmica. A Usina disponibiliza um "carro-pipa" para o abastecimento de água potável. Eles costumam, ainda, dissolver na água um repositor hidroeletrolítico que é utilizado, geralmente, por praticantes de atividade física intensa. Utilizam o filtro solar no rosto e protegem os braços e a nuca com vestimentas mais longos, que evitam o contato da pelo com os raios solares. Esses cuidados com o corpo refletem uma preocupação com a manutenção da boa condição física. Os cortadores dependem do bom condicionamento e também de boas condições de saúde para conseguir os dividendos para a sua manutenção, como também para poder levar as suas economias para a Bahia, no término do seu trabalho em Goiás. Os cortadores relatam, de forma bem-humorada, a sua aparência nas lavouras (Imagem 6). Um deles, mostrando as vestimentas pesadas e o corpo sujo pelas cinzas das queimadas, que misturado ao filtro solar formava uma massa escura e espessa, afirmou que nem a própria esposa o reconheceria nesse estado: "Aí depois que a gente tira (as cinzas do rosto) fica diferente. Você diz, esse aqui não é o (Baiano) que eu encontrei lá na roça. Ele é diferente (risos)."

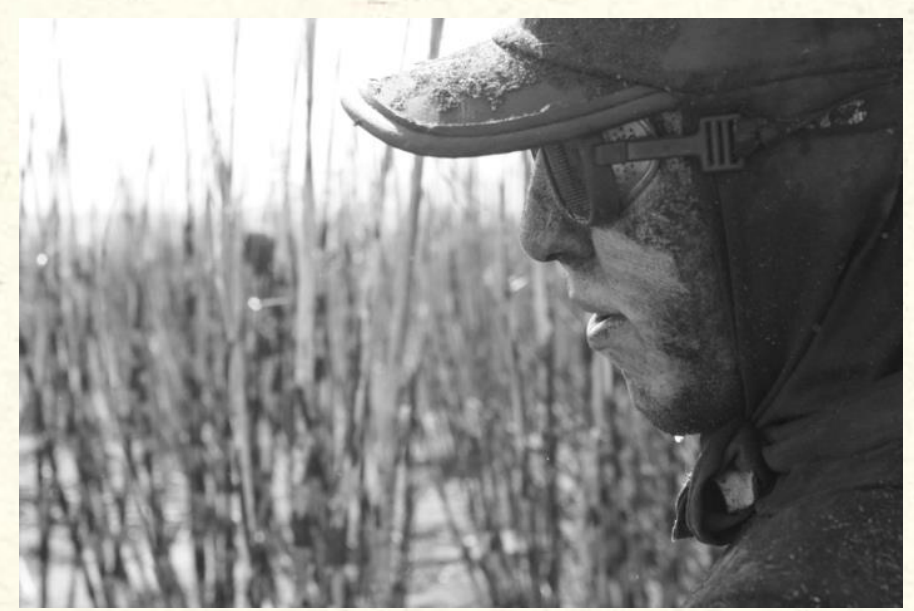

Imagem 6: "Diferente...A vida hoje é assim." Marcas da fuligem e das cinzas no rosto que transpira. Os equipamentos de proteção do rosto, além do filtro solar utilizado, e que permite o acúmulo de cinzas. Fotografia: Tiago de Oliveira Rabelo, Itapaci (G0), 2011.

Os intervalos são utilizados para as refeições e outras necessidades físicas. Os cortadores aproveitam ainda, para se comunicar com os familiares. Isso nos locais em que a comunicação via celular é possível na roça. Também utilizam para repor suas garrafas de água e tomar a sua solução hidroeletrolítica.

As questões em relação ao meio ambiente, ou a percepção ambiental desses trabalhadores não podem ser medidas pela sua atividade. Eles assumem uma postura que se assemelha à dos carvoeiros, que desmatam as florestas tropicais para a venda do carvão, e que muitas vezes, consideram 0 ambiente da selva natural mais belo do que a devastação carvoeira. Porém, se tornam indiferentes, na medida em que o sustento familiar é a sua prioridade. As questões envolvendo a produção de cana e desmatamento do cerrado não é parte das suas preocupações imediatas. No entanto, eles conseguem identificar 0 efeito das queimadas, sobretudo no que se refere à fauna, nos relatos sobre a "tirada do taião". Nesse serviço, que ocorre no dia seguinte da queima da lavoura, relatam sobre os animais silvestres carbonizados ou agonizando. Destacamos um trecho de um depoimento em que um cortador relata sobre a sua preocupação com as queimadas: "A gente lá vê tatu, veado. Já consegui ver morto um (tamanduá) bandeira. Esses dias mesmo, nós vimos um (tamanduá) bandeira sapecado no meio do 'taião'. Que nem esses dias mesmo, nós viu um bandeira sapecado no meio do taião. Sol quente. Passei a mão nele, levei debaixo do ônibus, molhei ele, dei água pra ele e soltei na mata. Falei, é da saúde dele. 
E provavelmente ele tava com a unha meio estragada, sabe? la caminhar, tava meio 'cachingando' aí. Agora, fiquei muito com dó dele. Aí eu soltei na mata. A gente no corte assim, a gente, até que é bom uma caninha queimada e tudo. A gente tem dó, que queima os bichinhos, num dá tempo dos bichinhos correr. Aqui tem hora que eles começam acender rodeando pra eles poder dá tempo de correr, mas quem tá lá do lado do que bota fogo, não alcança. Tem vez que a gente no corte mesmo, que nem em Inhumas, em Anicuns, quando tava queimando a cana, de dia mesmo queimava, sabe? Pra depois a gente cortar, a gente via as caça correndo. Tinha muita gente que ia até pra poder pegar. Eu dizia não, num pega o bichinho. Todo mundo quer viver, você não quer viver? Eu disse, deixa eles. Quando queima aí, vocês fica cum dó e tudo. Então deixa os bichinhos viver (sic)."

\section{Considerações finais}

A iconografia da produção canavieira no Brasil é um material rico para a explicação da história econômica e social do país. Desde o século XVII existe um acervo rico que retrata as paisagens antrópicas dos canaviais no Nordeste e Sudeste do Brasil. Além das paisagens antropizadas, a iconografia da atividade canavieira no Brasil evidenciou os processos sociais da atividade, na separação das classes, das camadas sociais hierarquizadas, como os senhores de engenho, os mestiços capatazes, os escravos africanos, bem como práticas, rotinas, afazeres dentre outros elementos da vida social. Também as tecnologias empregadas, nas diferentes formas de moendas, de engenhos e engenhocas. Alguns desses engenhos funcionavam de forma manual, outros eram movidos pela tração animal, pela força hidráulica.

A iconográfica também identificava os cenários devastados, cortes na floresta, queimadas, ou mesmo arquiteturas coloniais das mais diferentes condições sociais na vida nos engenhos. Esse trabalho se soma, de forma despretensiosa, a essa galeria de imagens da atividade canavieira no Brasil. São imagens que podem não se diferenciar de outras muito comuns nos canaviais do centro-sul brasileiro. Ou seja, não importa se no Cerrado, se na Mata Atlântica, se no solo do Planalto Central ou se nos massapês do Recôncavo Baiano ou nas terras roxas do oeste paulista e paranaense. São imagens que se repetem, e que irão se repetir, considerando as brechas e 0 prolongar da legislação brasileira em relação à queima da cana e, ao corte manual - elementos de uma mesma engrenagem. São imagens, no entanto, que procuram evidenciar não apenas o trabalho manual, mas as questões socioambientais que essa atividade suscita. 